\title{
An Orally Active Catalytic Metalloporphyrin Protects against 1-Methyl-4-Phenyl-1,2,3,6-Tetrahydropyridine Neurotoxicity In Vivo
}

\author{
Li-Ping Liang, ${ }^{1}$ Jie Huang, ${ }^{2}$ Ruth Fulton, ${ }^{1}$ Brian J. Day,,${ }^{1,2}$ and Manisha Patel ${ }^{1}$ \\ ${ }^{1}$ Department of Pharmaceutical Sciences, University of Colorado Health Sciences Center and ${ }^{2}$ Department of Medicine, National Jewish Medical and \\ Research Center, Denver, Colorado 80262
}

\begin{abstract}
Parkinson's disease (PD) is an age-related neurodegenerative disease in which the role of reactive oxygen species (ROS) is strongly implicated. The presence of oxidative stress has been detected in human and experimental PD using both direct and indirect indices. Scavenging ROS is, therefore, an important therapeutic avenue for the treatment of PD. Manganic porphyrins are catalytic antioxidants that scavenge a wide range of ROS. In this study, we tested the therapeutic effects of a compound [5,15-bis(methoxycarbonyl)-10,20-bistrifluoromethyl-porphyrinato manganese (III) chloride (AEOL11207)] belonging to a new generation of lipophilic manganic porphyrins for neuroprotection and oral bioavailability in the mouse 1-methyl-4-phenyl-1,2,3,6-tetrahydropyridine (MPTP) model of parkinsonism. Groups of adult C57BL/6 mice were administered MPTP with varying subcutaneous or oral dosing regimens of AEOL11207. Neurotoxicity was assessed by measurement of striatal dopamine levels and quantification of tyrosine hydroxylase-positive neurons in the substantial nigra pars compacta one week after the first dose of MPTP. Glutathione depletion, lipid peroxidation, and 3-nitrotyrosine (3-NT) formation were measured as indicators of oxidative stress in the ventral midbrain in vivo. AEOL11207 administered either by subcutaneous or oral routes protected against MPTP-induced dopamine depletion in the striatum as well as dopaminergic neuronal loss, glutathione depletion, lipid peroxidation, and 3-NT formation in the ventral midbrain. Neuroprotection correlated with brain metalloporphyrin concentrations. This is the first demonstration of neuroprotection by an orally active catalytic antioxidant in the MPTP mouse model and suggests its potential clinical utility for the treatment of chronic neurodegenerative diseases such as PD.
\end{abstract}

Key words: Parkinson's disease; oxidative stress; antioxidants; neuroprotection; dopamine; lipid peroxidation

\section{Introduction}

Free radical damage is strongly implicated as a mediator of dopaminergic neuronal death in Parkinson's disease (PD). Several convergent etiological factors associated with PD favor excessive free radical production. Chief among these are aging, mitochondrial dysfunction, protein aggregation, dopamine oxidation, and iron overload (Beal, 2005). The process of aging is one of the most important risk factors for developing PD and causes cumulative oxidative stress. Numerous studies have implicated mitochondrial oxidative stress and resultant dysfunction as an important mechanism in the pathogenesis of PD (Schapira et al., 1993; Beal, 1998). Inhibition of the mitochondrial electron transport chain at complex I is thought to be the primary biochemical lesion that may account for increased steady-state mitochondrial superoxide radicals $\left(\mathrm{O}_{2}{ }^{-}\right)$and subsequent hydrogen peroxide $\left(\mathrm{H}_{2} \mathrm{O}_{2}\right)$

Received Jan. 3, 2007; revised March 15, 2007; accepted March 16, 2007

This work is supported by National Institute of Neurological Disorders and Stroke Grant R01NS045748 (M.P.), Parkinson's Disease Foundation (L.P.L.), and Aeolus Pharmaceuticals (M.P., B.J.D.). We thank Ami Patel for technical assistance. B.J.D. is a consultant and holds equity in Aeolus Pharmaceuticals, which is commercially developing metalloporphyrins as potential therapeutic agents.

Correspondence should be addressed to Dr. Manisha Patel, Department of Pharmaceutical Sciences, 4200 East Ninth Avenue, Box C238, Denver, C0 80262. E-mail: manisha.pate@@uchsc.edu.

DOI:10.1523/JNEUROSCI.0019-07.2007

Copyright $\odot 2007$ Society for Neuroscience $\quad$ 0270-6474/07/274326-08\$15.00/0 production in human and animal models of PD (Schapira et al., 1989, 1990; Przedborski et al., 2001c). Posttranslational oxidative lesions of proteins such as $\alpha$-synuclein are thought to contribute to protein aggregation associated with PD (Giasson et al., 2000; Przedborski et al., 2001c). Several studies have shown that iron overload, a condition capable of increasing oxidative burden, occurs in PD patients and that iron chelators are protective (Sofic et al., 1988; Jellinger et al., 1990; Lan and Jiang, 1997). Finally, auto-oxidation of dopamine per se adds to the ongoing burden of oxidative stress to the vulnerable neurons in the substantia nigra pars compacta $(\mathrm{SNpc})$. In summary, oxidative stress associated with aging, mitochondrial dysfunction, protein aggregation, and iron overload is thought to contribute to the pathogenesis of PD (Beal, 2001).

The major therapeutic approach currently used to alleviate the symptoms of PD involves restoration of dopaminergic neurotransmission using levodopa, dopamine agonists, and inhibitors of monoamine metabolism. However, these therapeutic approaches are often associated with serious adverse effects and fail to provide long-term control of this inexorably progressive disease. Therefore, there is an urgent need for novel classes of therapeutic agents for the treatment of PD. Metalloporphyrins are a class of catalytic antioxidants that scavenge a wide range of reactive oxygen species (ROS) such as $\mathrm{O}_{2}{ }^{-}, \mathrm{H}_{2} \mathrm{O}_{2}$, peroxynitrite, and lipid peroxyl 


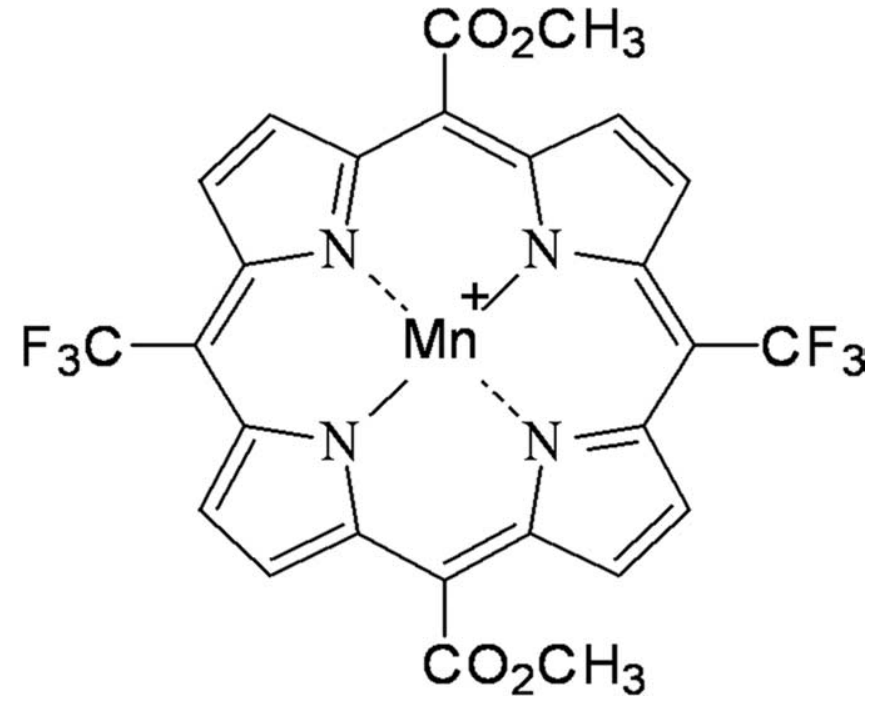

Figure 1. The chemical structure of AEOL11207.

radicals (Patel and Day, 1999). Several water-soluble metalloporphyrin compounds [manganese (III) meso-tetrakis(4carboxyphenyl)porphyrin, and manganese (III) meso-tetrakis ( $N, N^{\prime}$-diethylimidazolium-2-yl)porphyrin; AEOL10150] have been shown to be efficacious in animal models of CNS disorders including status epilepticus-induced injury (Liang et al., 2000), stroke (Mackensen et al., 2001), and amyotrophic lateral sclerosis (Crow et al., 2005).

Currently there are no catalytic antioxidants that are both orally active and readily penetrate the blood-brain barrier (BBB), which is a serious limitation in the treatment of chronic diseases. An orally active catalytic antioxidant that penetrates the $\mathrm{BBB}$ and possesses neuroprotective properties is highly desirable as a potential therapeutic agent for PD. Major drawbacks of the water-soluble pyridine [manganese tetrakis (2-ethyl) porphyrin] and imidazole-substituted metalloporphyrins are their poor lipophilicity and relatively modest BBB permeability. To overcome these issues, a series of novel glyoxylate metalloporphyrins with improved lipid solubility have been developed and characterized (Trova et al., 2003). The glyoxylate metalloporphyrins have been shown to possess high potencies in lipid peroxidation assays and their improved lipid solubility and smaller size is expected to allow them to better penetrate the blood-brain and gastrointestinal barriers. The goal of this study was to determine whether a representative glyoxylate manganese porphyrin $[5,15-$ bis(methoxycarbonyl)-10,20-bis-trifluoromethyl-porphyrinato manganese (III) chloride (AEOL11207)] (Figure 1) penetrates the $\mathrm{BBB}$ after parenteral and/or oral administration and attenuates 1-methyl-4-phenyl-1,2,3,6-tetrahydropyridine (MPTP) neurotoxicity in vivo.

\section{Materials and Methods}

Animals. Male C57BL/6 mice (8-10 weeks of age; $24-28$ g body weight) were purchased from Jackson Laboratory (Bar Harbor, MA). Animal experiments were performed in accordance with the National Institutes of Health Guide for the Care and Use of Laboratory Animals (NIH Publication No. 80-23) and approved by the Institutional Animal Care and Use Committee of the University of Colorado at Denver and Health Sciences Center (UCDHSC).

MPTP and metalloporphyrin administration. Groups of C57BL/6 mice were administered MPTP $(15 \mathrm{mg} / \mathrm{kg})$ via subcutaneous injection daily for $3 \mathrm{~d}$ either alone or in the presence of varying doses of AEOL11207 (5,
10,15 , or $25 \mathrm{mg} / \mathrm{kg}$ ) via per oral (p.o.) or subcutaneous injection, $1 \mathrm{~h}$ before MPTP and once daily thereafter for a total of 2, 3, or $5 \mathrm{~d}$. AEOL11207 was dissolved in dimethyl sulfoxide (DMSO) and diluted with sterilized PBS to achieve the desired final concentration (1\% DMSO). The control animals were injected with sterilized PBS containing 1\% DMSO. MPTP was dissolved in sterilized PBS. At different time points after MPTP treatment, mice were killed and their striata and ventral midbrain regions were dissected as described previously (Liang and Patel, 2004). The animal carcasses, needles, and MPTP waste products were disposed according to UCDHSC hazardous chemical disposal guidelines and as recommended in the literature (Przedborski et al., 2001a).

Determination of metalloporphyrin levels. C57BL/6 mice were injected by a subcutaneous or by per oral route with AEOL11207 $15 \mathrm{mg} / \mathrm{kg}$ and killed at different time points for pharmacokinetic analysis. Mice were deeply anesthetized by phenobarbital and plasma was collected by cardiac puncture. Mice were perfused with heparinized saline to remove blood in the brain. Brains were dissected and snap-frozen in liquid nitrogen. For AEOL11207 analysis, plasma samples were extracted and deproteinated with $50 \%$ methanol and $0.02 \mathrm{~N}$ perchloric acid (PCA), respectively. Brain samples $(\sim 100 \mathrm{mg})$ were sonicated in a $12.5 \%(\mathrm{w} / \mathrm{v})$ methanol solution containing $0.05 \mathrm{~N}$ PCA. Manganese (III) tetrakis (methoxy carbonyl) porphyrin chloride, a structural analog of AEOL11207, was added to the samples as an internal standard. All samples were centrifuged at 20,000 $\times g$ for $10 \mathrm{~min}$ and the supernatants filtered through a $0.22 \mu \mathrm{m}$ filter. An aliquot of supernatant $(10 \mu \mathrm{l})$ was injected into an HPLC machine equipped with a UV detector set at $450 \mathrm{~nm}$ as described previously (Kachadourian et al., 2002). Recovery of AEOL11207 from plasma and brain samples was determined to be $\sim 98 \%$.

Measurement of dopamine and DOPAC. Striatal dopamine and 3,4dihydroxyphenylacetic acid (DOPAC) levels were determined using a previously described method by HPLC equipped with an electrochemical detector (Liang and Patel, 2004).

Analysis of striatal MPP ${ }^{+}$levels. Striatal 1-methyl-4-phenylpyridinium $\left(\mathrm{MPP}^{+}\right)$levels were determined as described previously (Liang and $\mathrm{Pa}-$ tel, 2004). MPP ${ }^{+}$was analyzed by HPLC equipped with a UV detector set at $295 \mathrm{~nm}$. The mobile phase $(30 \%$ acetonitrile and $0.02 \mathrm{M}$ potassium phosphate, adjusted to $\mathrm{pH} 2.5$ with $\mathrm{H}_{3} \mathrm{PO}_{4}$ ) was delivered at a flow rate of $0.5 \mathrm{ml} / \mathrm{min}$ on a YMC ODS column $3 \mu \mathrm{m}, 150 \times 4.6 \mathrm{~mm}$ (Waters, Milford, MA).

Stereological analysis and TH immunohistochemistry. Brain blocks containing the midbrain $(\sim 4 \mathrm{~mm}$ thick) were fixed in $4 \%$ paraformaldehyde in $0.1 \mathrm{M} \mathrm{PBS}, \mathrm{pH} 7.4$ for $24 \mathrm{~h}$. The blocks were transferred to PBS containing $30 \%$ sucrose and further incubated for $24 \mathrm{~h}$. Midbrain blocks that included the ventral midbrain region including the SNpc from bregma -2.60 to $-3.80 \mathrm{~mm}$ were frozen and cut into $40 \mu \mathrm{m}$ sections using a cryostat. Every fourth section of the midbrain region was immunostained with a rabbit antibody to tyrosine hydroxylase (TH; Millipore, Temecula, $\mathrm{CA}$ ) using the $\mathrm{ABC}$ method (ABC Elite Kit; Vector Laboratories, Burlingame, $\mathrm{CA}$ ). The number of TH-positive neurons were quantified using a Nikon (Melville, NY) Optiphot-2 80i microscope equipped with stereo investigator software (MicroBrightfield, Williston, VT) using a previously described method (West, 1999). After defining the boundary of the SNpc at low magnification ( $4 \times$ objective), $\mathrm{TH}$ positive neurons in sections from the entire $\mathrm{SNpc}$ were counted at higher magnification $(60 \times$ objective) using the optical fractionator method by an investigator (R.F.) who was blinded to the treatments. Photomicrographs (see Fig. $5 B$ ) were taken from $6 \mu \mathrm{m}$ sections after the TH immunohistochemical staining protocol described above.

3-NT measurement by HPLC. 3-Nitrotyrosine (3-NT) assay was performed with ESA (Chelmsford, MA) 5600 CoulArray HPLC equipped with eight electrochemical detector cells using methods described previously in the literature (Beal et al., 1990; Hensley et al., 1998). The potentials of the electrochemical detector were set at 180/240/350/500/600/ $670 / 810 / 830 \mathrm{mV}$. Analyte separation was conducted on a Tosohaas (Montgomeryville, PA) reverse-phase ODS 80-TM C-18 analytical column $(4.6 \mathrm{~mm} \times 250 \mathrm{~cm} ; 5 \mu \mathrm{m}$ particle size $)$. A two-component gradient elution system was used with component $\mathrm{A}$ of the mobile phase composed of $50 \mathrm{~mm}$ sodium acetate, $\mathrm{pH} 3.2$, and component $\mathrm{B}$ composed of 
$50 \mathrm{~mm}$ sodium acetate and $40 \%$ methanol. The following gradient elution profile was used: $0-25 \mathrm{~min}, 100 \% \mathrm{~A} ; 25-35 \mathrm{~min}$, linear ramp to $50 \%$ $\mathrm{B} ; 35-40 \mathrm{~min}$, isocratic $50 \% \mathrm{~B} ; 40-45 \mathrm{~min}$, linear ramp to $100 \% \mathrm{~A} ; 45-50$ min, isocratic $100 \% \mathrm{~A}$ at a flow rate of $0.6 \mathrm{ml} / \mathrm{min}$. Samples prepared from the ventral midbrain were sonicated in ice-cold $0.1 \mathrm{M}$ PCA, centrifuged at $16,000 \times g 4^{\circ} \mathrm{C}$ for $10 \mathrm{~min}$, and aliquots $(50 \mu \mathrm{l})$ of the supernatant were injected into the HPLC machine. The retention times of tyrosine and 3-NT were 25.63 and $40.25 \mathrm{~min}$, respectively. 3-NT was expressed as a ratio of 3-NT to tyrosine.

Determination of 4-HNE. For in vitro lipid peroxidation studies, homogenates from the rat forebrain were prepared in $50 \mathrm{~mm}$ Tris- $\mathrm{HCl}$ buffer, pH $7.4(20 \% \mathrm{w} / \mathrm{v})$. Homogenates $(200 \mu \mathrm{l})$ were incubated at $37^{\circ} \mathrm{C}$ for 10 min with varying concentrations of AEOL11207 (final concentrations ranged from $30 \mathrm{~nm}$ to $30 \mu \mathrm{M}$ ). Freshly made $\mathrm{FeCl}_{2}$ and ascorbate were added at a final concentration of $25 \mu \mathrm{M}$ and $0.1 \mathrm{~mm}$, respectively, and incubated at $37^{\circ} \mathrm{C}$ for 6 h. 4-Hydroxy-2-nonenal (4-HNE) was extracted using $200 \mu \mathrm{l}$ of $80 \%$ acetonitrile and $0.2 \mathrm{~N}$ PCA added to each tube (final concentration, $40 \%$ acetonitrile and $0.1 \mathrm{~N} \mathrm{PCA}$ ) and incubated at room temperature for $10 \mathrm{~min}$. The homogenates were centrifuged at $13,000 \times g 4^{\circ} \mathrm{C}$ for $10 \mathrm{~min}$. Aliquots $(50 \mu \mathrm{l})$ of the supernatant were injected into the HPLC machine for 4-HNE measurement.

4-HNE measurement in rat brain homogenates or ventral midbrain tissue was conducted according to the methods described previously by Murphy et al. (2003). The tissue was weighed and sonicated in 20\% (w/v) of $0.1 \mathrm{~N} \mathrm{PCA}$ and $40 \%$ acetonitrile immediately before thawing to prevent artificial formation of 4-HNE during sample preparation. The homogenates were incubated at room temperature for $10 \mathrm{~min}$ to extract 4-HNE and centrifuged at $13,000 \times g$ at $4^{\circ} \mathrm{C}$ for $15 \mathrm{~min}$. Aliquots $(50 \mu \mathrm{l})$ of the supernatant were injected into HPLC. 4-HNE was analyzed using a Cou1Array system with the UV detector set at $221 \mathrm{~nm}$ and a $5 \mu \mathrm{m}, 150 \times 4.6$ mm YMC ODS-A C18 column (Waters). The mobile phase was composed of $35 \%$ acetonitrile plus $0.3 \%(\mathrm{w} / \mathrm{v})$ phosphoric acid and the flow rate was set at $0.8 \mathrm{ml} / \mathrm{min}$. The retention time of $4-\mathrm{HNE}$ was $7.87 \mathrm{~min}$. 4 -HNE levels were expressed as nanograms per gram of tissue. Protein concentrations were measured using Coomassie Plus reagents (Pierce, Rockford, IL).

Measurement of reduced GSH and GSSG. Glutathione (GSH) and glutathione disulfide (GSSG) were measured by HPLC equipped with electrochemical detection as described previously (Lakritz et al., 1997; Liang and Patel, 2006). Electrochemical detector potentials were 120/355/480/ 560/700/820 mV.

SOD activity assay. Superoxide dismutase (SOD) activity was measured in brain homogenates by the adrenochrome assay as described by Misra and Fridovich (1972).

Statistical analyses. For comparison of three or more treatments groups, one-way ANOVA with Tukey's post hoc test was used. $p$ values $<0.05$ were considered significant.

\section{Results \\ AEOL11207 penetrates the BBB after subcutaneous or per oral administration}

To determine AEOL11207 bioavailability in vivo, we measured its concentration in the plasma and brains of C57BL/6 mice at different time points after a single $15 \mathrm{mg} / \mathrm{kg}$ dose given by either subcutaneous or oral administration by gavage. AEOL11207 levels were detected $1 \mathrm{~h}$ after administration, peaked at $4 \mathrm{~h}$ and remained stable at $\sim 3-4 \mu \mathrm{M}$ in plasma for $4 \mathrm{~d}(96 \mathrm{~h})$ regardless of the route of administration (Fig. $2 \mathrm{~A}$ ). Plasma and brain levels after subcutaneous administration remained steady for several more days before declining; drug clearance from the plasma compartment occurred more rapidly than the brain (Fig. 2A,B). Plasma elimination half-life of AEOL11207 was estimated to be $5 \mathrm{~d}$. Brain concentrations of AEOL11207 rose steadily for $4 \mathrm{~d}$ (96 h) and stabilized at $\sim 200 \mathrm{~nm}$ regardless of the route of administration (Fig. $2 B$ ). It is noteworthy that this concentration is similar to the effective antioxidant concentration of this compound $(\sim 70 \mathrm{nM})$ based on $\mathrm{IC}_{50}$ inhibition of 4 -HNE in rat brain homog-
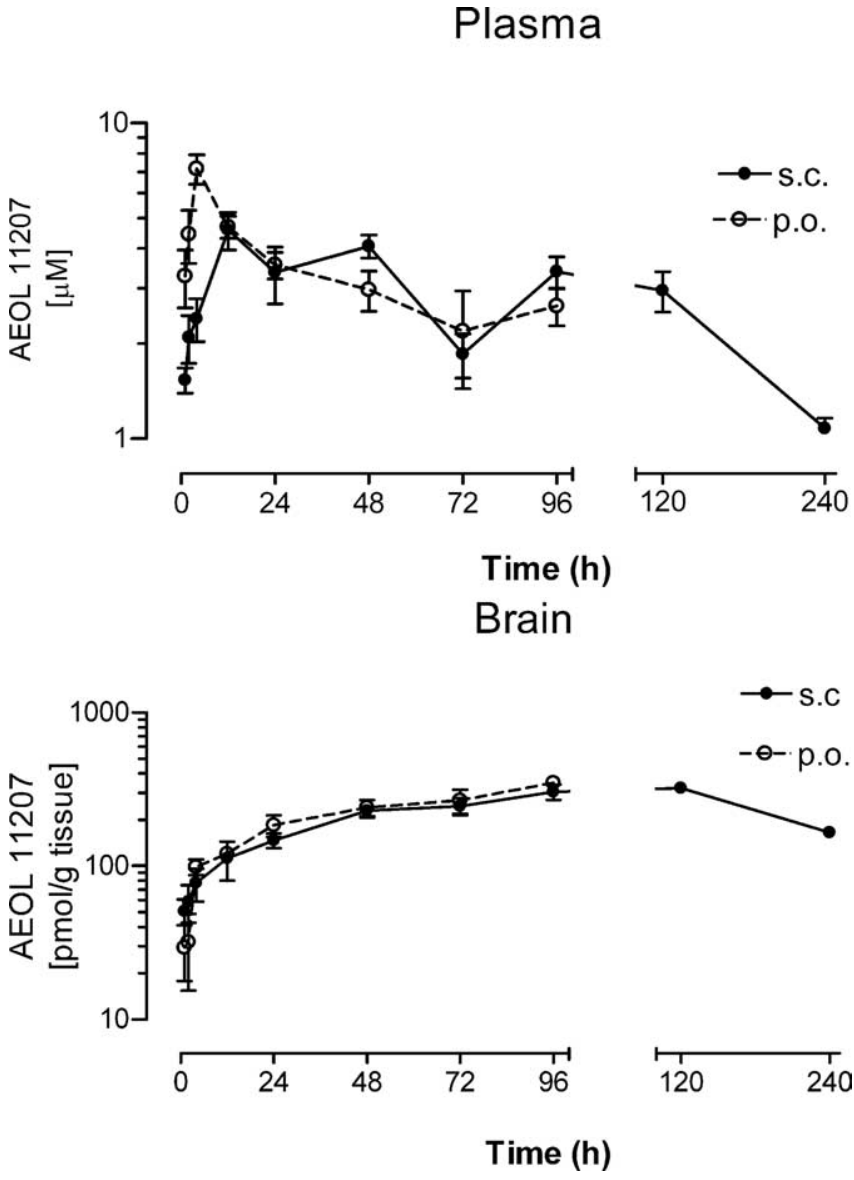

Figure 2. AEOL11207 penetrates the BBB after subcutaneous or per oral administration. $A$, $\boldsymbol{B}$, The concentration of AEOL11207 in the plasma $(\boldsymbol{A})$ and brains $(\boldsymbol{B})$ of the $(57 \mathrm{BL} / 6$ mice at different times points after a single dose of AEOL11207 $(15 \mathrm{mg} / \mathrm{kg})$ administered by the subcutaneous or per oral route. Points and error bars represent mean + SEM. Each point is the average of $3-4$ animals.

Table 1. Antioxidant properties of metalloporphyrins

\begin{tabular}{llll}
\hline Agent code or chemical & SOD activity (U/mg) & CAT (1/min) & 4-HNE IC 50 (nm) \\
\hline Native Cu-Zn SOD & 15,267 & - & - \\
AEOL10150 & 43,103 & 2.2 & 271 \\
AE0L11207 & 124 & 1.54 & 71
\end{tabular}

SOD activity, Unit of SOD activity is defined as the amount of compound that inhibits one-half the formation of adrenochrome by superoxide at $\mathrm{pH}$ 10.2. CAT, Catalase activity is measured by a Clarke-type oxygen electrode (Trova et al., 2003). 4-HNE IC ${ }_{50}$, The concentration (nanomolars) of compound required to inhibit 50\% 4-HNE formation in rat brain homogenates treated with $\mathrm{FeCl}_{2}$ and ascorbate. For details, see Materials and Methods.

enates (Table 1). The results suggest that AEOL11207 has a long plasma and brain half-life and can be absorbed by the gastrointestinal tract. Furthermore, the results suggest that AEOL11207 readily passes the $\mathrm{BBB}$, accumulates in the brain, and maintains concentrations sufficient to inhibit oxidative stress for a prolonged duration.

\section{AEOL11207 attenuates MPTP-induced striatal dopamine depletion}

Based on its favorable pharmacokinetic profile, the effects of AEOL11207 admininstered by the subcutaneous and per oral routes were examined in the MPTP mouse model of experimental PD. A dosing regimen for MPTP administration consisting of $15 \mathrm{mg} / \mathrm{kg}$ subcutaneous daily for $3 \mathrm{~d}$ was selected based on its ability to lower striatal dopamine levels by $\sim 75 \%$. The dosing regimen for AEOL11207 was varied to optimize its ability to pro- 
A

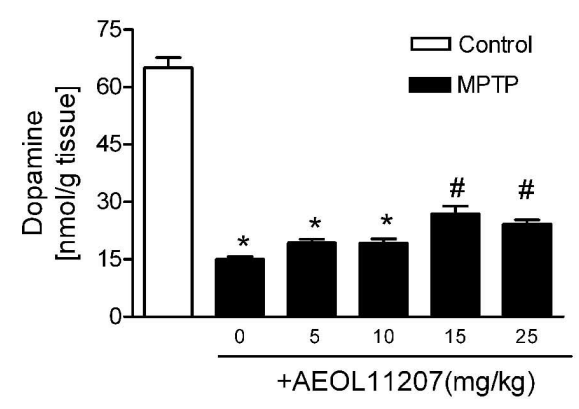

C

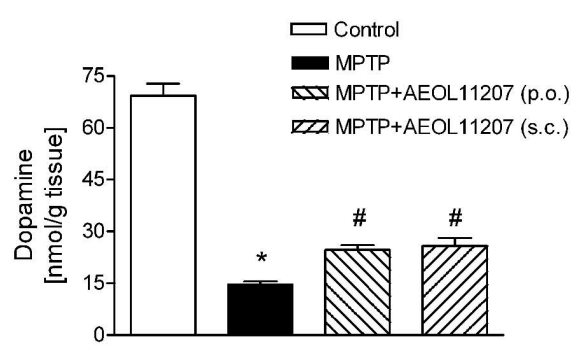

B

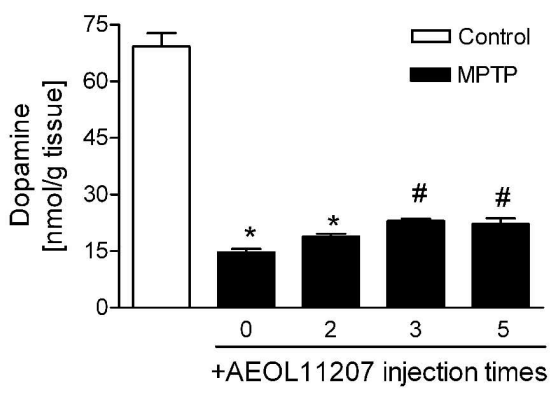

D

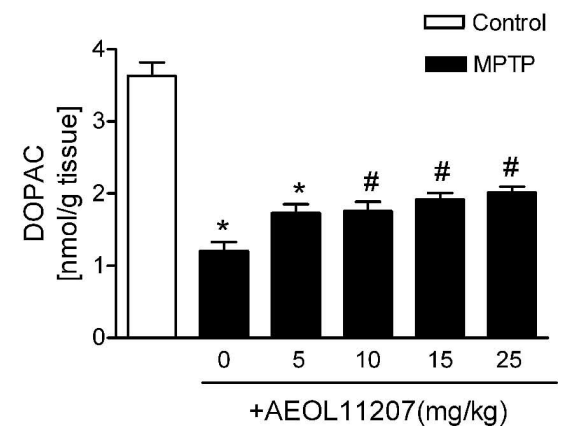

Figure 3. AEL011207 attenuates MPTP-induced dopamine depletion. A-C, Striatal dopamine levels in C57BL/6 mice $7 \mathrm{~d}$ after injection of MPTP (15 mg/kg $\times 3$, s.c., $24 \mathrm{~h}$ intervals) alone or in the presence of varying doses $(5,10,15$, or $25 \mathrm{mg} / \mathrm{kg}, \mathrm{s.c}, 1 \mathrm{~h}$ before MPTP and daily thereafter for total $3 \mathrm{~d}$ ) of AEOL11207 (A), after varying injection times ( $15 \mathrm{mg} / \mathrm{kg}$, s.C., $1 \mathrm{~h}$ before MPTP and daily thereafter for a total of 2, 3, or 5 times) of AEOL11207 (B), or after different administration routes ( $\boldsymbol{C}$ ). Error bars represent mean + SEM. ${ }^{*} p<0.01$ versus control; ${ }^{\#} p<0.05$ versus MPTP; one-way ANOVA; $n=6$ mice per group.

by the per oral or subcutaneous route. AEOL11207 administration alone at the doses tested did not have any significant effect on striatal dopamine and DOPAC levels (data not shown). AEOL11207 attenuated MPTP-induced DOPAC depletion in the striatum (Fig. 1D). However, AEOL11207 did not alter the DOPAC/dopamine ratio, an index of dopamine turnover, either alone or in presence of MPTP (data not shown).

\section{Striatal MPP ${ }^{+}$levels are not altered by AEOL11207}

Because MPTP neurotoxicity to the nigrostriatal system is dependent on its metabolism to an active metabolite $\mathrm{MPP}^{+}$in the striatum (Giovanni et al., 1991), the ability of AEOL11207 to alter striatal $\mathrm{MPP}^{+}$levels was determined. No significant changes were observed in striatal $\mathrm{MPP}^{+}$levels between groups of mice injected with MPTP alone and MPTP in the presence of AEOL11207 (15 mg/kg, s.c.) measured 3 and $24 \mathrm{~h}$ after a single dose of MPTP (15 mg/kg) (Fig. 4). This suggests that the subsequently tested effects of AEOL11207 on MPTP neurotoxicity are not caused by altered MPTP metabolism via inhibition of monoamine oxidase and/or bioavailability.

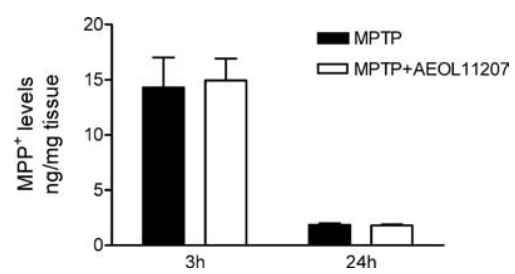

Figure 4. Striatal MPP + levels are not altered by AEOL11207. Striatal MPP ${ }^{+}$levels 3 and $24 \mathrm{~h}$ after MPTP (15 mg/kg, s.c.) alone or in the presence of AEOL11207 (15 mg/kg, s.c.), $1 \mathrm{~h}$ before MPTP treatment. Error bars represent mean + SEM. $n=6$ mice per group.

tect against MPTP-induced striatal dopamine depletion. Doseresponse studies revealed that a significant protective effect against MPTP-induced striatal dopamine depletion was observed with AEOL11207 doses of 15 or $25 \mathrm{mg} / \mathrm{kg}$, but not 5 or $10 \mathrm{mg} / \mathrm{kg}$ after three injections once daily by the subcutaneous route (Fig. $3 A$ ). We further examined whether MPTP-induced dopamine depletion was altered by fewer or additional doses of AEOL11207. No significant protection was afforded by two doses (once daily). Furthermore, no additional beneficial effect was observed after five doses (once daily) compared with three doses of $15 \mathrm{mg} / \mathrm{kg}$, subcutaneous AEOL11207 (Fig. 3B). Administration via the per oral route showed a similar level of protection against dopamine depletion compared with administration via the subcutaneous route after three doses of $15 \mathrm{mg} / \mathrm{kg}$ AEOL11207 (Fig. 3C). Similar to the subcutaneous administration, two doses of AEOL11207 via the per oral route did not provide significant protection and five doses did not have additional protection compared with three doses (data not shown). Therefore, for subsequent analysis of oxidative stress and neuroprotection, the dosing regimen consisted of $15 \mathrm{mg} / \mathrm{kg}$ AEOL11207 injections for three d, once daily

\section{AEOL11207 protects against MPTP-induced loss of TH- positive SNpc cells}

To examine whether AEOL11207 attenuates the selective loss of dopaminergic neurons after MPTP administration, stereological analysis of the number of TH-positive cells in defined SNpc of the mouse was performed $7 \mathrm{~d}$ after the first injection of MPTP. MPTP-treated mice showed a 58\% loss of TH-positive dopaminergic neurons in the SNpc compared with saline-treated mice (Fig. 5). Administration of AEOL11207 either via subcutaneous or per oral routes significantly protected against the loss of SNpc dopamine neurons compared with control mice treated with MPTP alone (Fig. 5A,B). The number of SNpc TH-positive neurons did not change significantly after treatment with AEOL11207 alone (data not shown).

AEOL11207 protects against MPTP-induced oxidative stress Finally, we measured the cell-free antioxidant potency of AEOL11207 to determine whether this correlated with the brain concentrations achieved in Figure 2 and neuroprotection in vivo. The glyoxylate series of manganese porphyrins have been shown previously to be potent inhibitors of iron and ascorbate mediated lipid peroxidation in rat brain homogenates and possess catalase activity (Gauuan et al., 2002). To determine the optimal assay for the measurement of in vivo antioxidant activity of AEOL11207, we compared its in vitro antioxidant potencies with an imidazole metalloporphyrin with high SOD activity (AEOL10150). In comparison with AEOL10150 and Cu-Zn SOD (Sigma, St. Louis), AEOL11207 possessed low SOD activity ( 350 times lower), but roughly equivalent catalase activity (Table 1). However, AEOL11207 was highly potent as an inhibitor of lipid peroxidation with an $\mathrm{IC}_{50}$ value of $71 \mathrm{nM}$, which is $\sim 3.8$ times higher than 
AEOL10150 ( $\mathrm{IC}_{50}$ value $\left.271 \mathrm{~nm}\right)$. The ability of AEOL11207 to inhibit lipid peroxidation was therefore measured as one in vivo indicator of oxidative stress. 4-HNE levels were also measured as an index of lipid peroxidation because (1) it is the major product of total unsaturated aldehydes formed during lipid peroxidation (Benedetti et al., 1980), (2) it is shown to be generated in 100-fold excess over malondialdehyde (MDA) during oxidation of arachidonic acid (Mlakar and Spiteller, 1996), and (3) levels of 4-HNE but not MDA are increased in Alzheimer's disease brains (McGrath et al., 2001). Measurement of 4-HNE levels in the ventral midbrain $24 \mathrm{~h}$ after MPTP treatment showed a nearly threefold increase compared with the saline-injected mice (Fig. 6A), consistent with a previous report (Selley, 1998). AEOL11207 significantly inhibited MPTP-induced increase of 4-HNE (Fig. 6A).

$3-\mathrm{NT}$ is formed in proteins after the reaction of tyrosine residues with nitrating oxidants (Ischiropoulos et al., 1992). 3-NT formation is a well documented marker of oxidative damage to proteins in both human PD tissue and MPTP-treated mice (Schulz et al., 1995; Good et al., 1998; Pennathur et al., 1999). Therefore, we determined the effect of AEOL11207 on free 3-NT levels in the mouse ventral midbrain. Compared with vehicle-treated mice, free 3-NT concentrations increased twofold in the mouse ventral midbrain region $24 \mathrm{~h}$ after the last dose of MPTP (Fig. $6 \mathrm{~B})$. This result is consistent with previously reported measurements of free 3-NT by HPLC (Schulz et al., 1995) or protein 3-NT by mass spectrometry (Pennathur et al., 1999). Administration of AEOL11207 significantly attenuated MPTP-induced increase of free 3-NT levels (Fig. 6B). No significant changes in free 3-NT were observed in the frontal cortex after MPTP treatment (data not shown), suggesting selectivity of MPTP-induced oxidative damage to the ventral midbrain region that contains the vulnerable SNpc neurons.

To further link the neuroprotective effects of AEOL11207 with antioxidant actions, we measured GSH and GSSG as indicators of cellular redox status in the mouse ventral midbrain region. After MPTP treatment, the levels of GSH were modestly depleted (18\%) (Fig. 6D); whereas the corresponding levels of GSSG were significant increased (300\%) (Fig. 6E). AEOL11207 administered via the oral route significantly restored GSH, GSSG, and GSH/ GSSG ratios (Fig. 6C-E).

\section{Discussion}

In this study we demonstrate the following principal findings. First, a newly developed lipophilic metalloporphyrin AEOL11207 penetrates the BBB after subcutaneous and oral administration with a long plasma and brain half-life. Second, AEOL11207 significantly attenuates MPTP-induced striatal do-
B
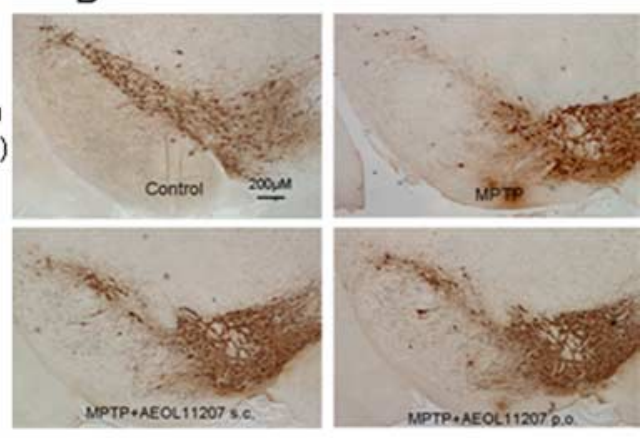

MPTP.AEOL $11207 \%$.

Figure 5. AEOL11207 protects against MPTP-induced loss of TH-positive SNpc cells. $\boldsymbol{A}$, TH-positive neurons in the SNpc of

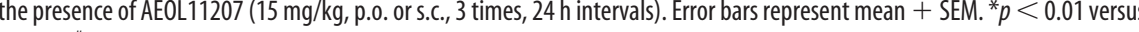
control; ${ }^{*} p<0.05$ versus MPTP; one-way ANOVA; $n=5-6$ mice per group. $B$, Representative TH immunohistochemical staining
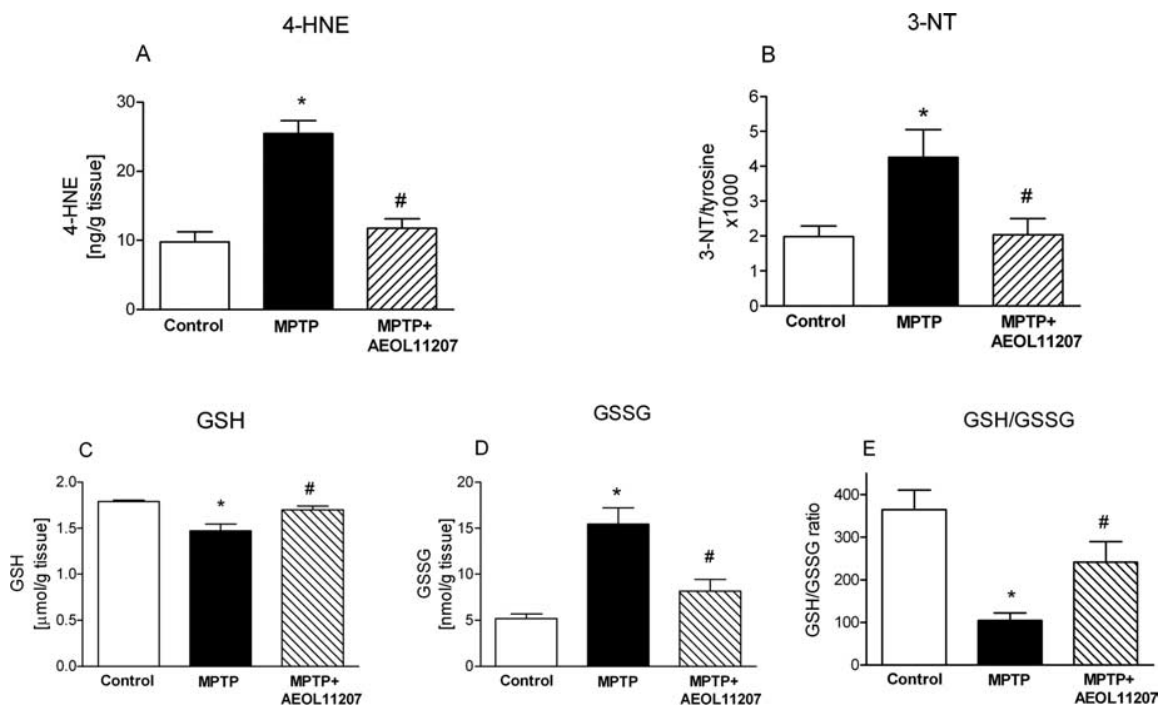

Figure 6. AEOL11207 attenuates MPTP-induced free 3-NT formation and lipid peroxidation. $\boldsymbol{A}-\boldsymbol{E}$, Levels of 4-HNE $(\boldsymbol{A})$, 3-NT $(\boldsymbol{B})$, GSH $(\boldsymbol{C})$, GSSG $(\boldsymbol{D})$, and ratio of GSH/GSSG $(\boldsymbol{E})$ in the ventral midbrain region of C57BL/6 mice $24 \mathrm{~h}$ after MPTP $(15 \mathrm{mg} / \mathrm{kg}, 3$ times, S.C., $24 \mathrm{~h}$ intervals) alone or in the presence of AEOL11207 per oral (15 mg/kg, 3 times, $24 \mathrm{~h}$ intervals). Error bars represent mean + SEM. ${ }^{*} p<0.05$ versus control; ${ }^{*} p<0.01$ versus MPTP; one-way ANOVA; $n=6$ mice per group.

pamine depletion and dopaminergic neuronal death in the SNpc after subcutaneous or oral administration without interfering with MPTP metabolism. Finally, AEOL11207 inhibits MPTPinduced oxidative damage in vivo. This is the first demonstration to our knowledge of protection by an orally active metal-based catalytic antioxidant in an experimental model of PD.

Our data suggest that AEOL11207 has a long plasma half-life and rapid absorption by the gastrointestinal tract. Importantly, the results suggest that AEOL11207 passes the BBB and accumulates in the brain for a prolonged period at pharmacologically relevant concentrations that exceed its ability to inhibit lipid peroxidation in vitro. Together, these favorable pharmacokinetic properties of AEOL11207 enable it to fulfill the current void of an orally active manganic porphryin for the treatment of chronic neuronal disorders. In this study, we observed a discrepancy in the extent to which AEOL 11207 protected TH-positive neurons versus striatal dopamine depletion. Because restoration of dopamine levels correlates best with symptomatic relief of $\mathrm{PD}$, the therapeutic implications of AEOL11207 in PD may be primarily 
as a neuroprotective agent or adjunct therapy with currently available drugs that restore dopamine levels.

Demonstration of neuroprotection by oral administration of a metal-based catalytic antioxidant is consistent with a large body of literature that suggests oxidative stress as a major therapeutic target for PD. Direct oxidative damage to proteins, lipids, and DNA has been detected in the substantia nigra from human and experimental PD (Dexter et al., 1989, 1994a; Alam et al., 1997a,b; Good et al., 1998; Giasson et al., 2000; Przedborski et al., 2001b; Fessel et al., 2003). Indirect evidence for oxidative stress in PD comes from studies showing decreased glutathione, increased iron levels and antioxidant imbalance (Perry et al., 1982; Dexter et al., 1987; Sian et al., 1994; Ara et al., 1998; Jha et al., 2000). Moreover, the role of oxidative mechanisms in the pathogenesis of PD is favored by the knowledge that aging is the most important risk factor for developing PD. Using transgenic approaches, detailed studies have suggested the role of cytosolic, mitochondrial, and extracellular ROS in MPTP neurotoxicity (Przedborski et al., 1992; Klivenyi et al., 1998; Wu et al., 2003). Furthermore, oxidative stress is a common mediator of several genetic causes of PD (Dauer and Przedborski, 2003). Posttranslational oxidative lesions of proteins (e.g., $\alpha$-synuclein and DJ-1) are thought to contribute to protein aggregation associated with PD (Giasson et al., 2000; Przedborski et al., 2001c).

Inhibition of lipid peroxidation and catalytic scavenging of reactive species are the most likely mechanisms by which AEOL11207 exerts neuroprotection in our studies. Lipid peroxidation is a well-known mechanism of cellular injury initiated by ROS (Sayre et al., 2001) and numerous studies have demonstrated its role in the pathogenesis of PD (Dexter et al., 1989, 1994a; Fessel et al., 2003). The hydroaldehydes, MDA and particularly 4-HNE, are the most cytotoxic aldehydes produced in the process of lipid peroxidation (Esterbauer et al., 1991; Beal, 2002). Significantly higher concentrations of 4-HNE have been observed in the brains of PD patients and mouse models of PD (Yoritaka et al., 1996; Selley, 1998).

GSH is the most abundant thiol containing antioxidant in tissues including the brain (Meister and Anderson, 1983) and plays an important role in preventing oxidative damage. GSH is a unique antioxidant in that it possesses intrinsic antioxidant activity as well as serving as a cofactor for a number of cellular detoxification pathways. GSH serves to detoxify $\mathrm{H}_{2} \mathrm{O}_{2}$ and helps maintain the cysteinyl-thiol $\left(\mathrm{R}-\mathrm{CH}_{2}-\mathrm{SH}\right)$ groups of proteins in the reduced state, which is often necessary for their function. GSH and its oxidized form, GSSG, have been the most commonly used biomarker of oxidative stress in biological systems (Reed and Savage, 1995). A depletion of GSH levels has been observed in the substantia nigra of PD patients and in the MPTP model (Perry et al., 1982; Bannon et al., 1984; Ferraro et al., 1986; Sian et al., 1994). Furthermore, it has been established that GSH loss is an early event in PD, occurring even in presymptomatic patients (Dexter et al., 1994b) suggesting that glutathione depletion may be a crucial factor in the progression of PD (Jenner et al., 1992). In our studies, the decrease in GSH/GSSG ratio paralleled the increase in 4-HNE formation and overt dopaminergic cell loss. The depletion of GSH in the ventral midbrain of mice after MPTP treatment may be in part caused by the formation of 4-HNE and its subsequent conjugation with GSH (Selley, 1998). The ability of AEOL11207 to attenuate MPTP-induced formation of 4-HNE and GSH depletion is consistent with its lipid peroxidation inhibitory and catalase activities. Because oxidative stress response after MPTP administration in vivo involves mitochondrial, extracellular, and cytosolic compartments, secondary production of
$\mathrm{H}_{2} \mathrm{O}_{2}$ and metal catalyzed hydroxyl radicals can initiate glutathione depletion and lipid peroxidation, respectively.

Increases in protein and free 3-NT have been well documented in human and experimental PD (Schulz et al., 1995; Pennathur et al., 1999). 3-NT immunoreactivity has been identified in Lewy bodies and amorphous deposits within intact and degenerating neurons of the substantia nigra from PD patients (Good et al., 1998). The ability of AEOL11207 to inhibit MPTP-induced free 3-NT formation in the ventral midbrain, a region containing the vulnerable SNpc neurons is additional evidence of its antioxidant mechanism. The precise mechanism by which AEOL11207 attenuated 3-NT formation remains to be determined but may involve inhibition of the formation of nitrating species.

Although neuroprotection by AEOL11207 correlated with its ability to attenuate oxidative stress, two important issues remain to be resolved. First, because MPTP neurotoxicity involves the production of ROS from both intracellular and extracellular compartments via neurons and microglia, respectively, the primary cellular compartment in which AEOL11207 exerts its antioxidant action remains to be determined. This analysis is complicated because of the transient and unstable nature of reactive species as well as challenges associated with accurate assessment of compartmentalized and cell-type specific ROS production in the in vivo setting. Second, alternate mechanisms independent of direct antioxidant effects may also have contributed to the neuroprotective effect of AEOL11207. For example, antiinflammatory agents are markedly neuroprotective in the MPTP model where striking inflammatory changes occur concurrently with oxidative stress (Gao et al., 2003; Wu et al., 2003; Choi et al., 2005). The precise mechanism and cellular compartment from which AEOL11207 removes reactive species and whether mechanisms other than a direct antioxidant effect contribute to its neuroprotective effect are areas of future investigation in our laboratory.

In summary, our data suggests that AEOL11207, a novel metalloporphyrin catalytic antioxidant has favorable BBB permeability after oral or subcutaneous administration and is neuroprotective in an in vivo model of Parkinsonism. This finding may have implications for further clinical development of this class of compounds for the treatment of neurodegenerative diseases.

\section{References}

Alam ZI, Jenner A, Daniel SE, Lees AJ, Cairns N, Marsden CD, Jenner P, Halliwell B (1997a) Oxidative DNA damage in the parkinsonian brain: an apparent selective increase in 8-hydroxyguanine levels in substantia nigra. J Neurochem 69:1196-1203.

Alam ZI, Daniel SE, Lees AJ, Marsden DC, Jenner P, Halliwell B (1997b) A generalised increase in protein carbonyls in the brain in Parkinson's but not incidental Lewy body disease. J Neurochem 69:1326-1329.

Ara J, Przedborski S, Naini AB, Jackson-Lewis V, Trifiletti RR, Horwitz J, Ischiropoulos H (1998) Inactivation of tyrosine hydroxylase by nitration following exposure to peroxynitrite and 1-methyl-4-phenyl-1,2,3,6tetrahydropyridine (MPTP). Proc Natl Acad Sci USA 95:7659-7663.

Bannon MJ, Goedert M, Williams B (1984) The possible relation of glutathione, melanin and 1-methyl-4-phenyl-1,2,5,6-tetrahydropyridine (MPTP) to Parkinson's disease. Biochem Pharmacol 33:2697-2698.

Beal MF (1998) Mitochondrial dysfunction in neurodegenerative diseases. Biochim Biophys Acta 1366:211-223.

Beal MF (2001) Experimental models of Parkinson's disease. Nat Rev Neurosci 2:325-334.

Beal MF (2002) Oxidatively modified proteins in aging and disease. Free Radic Biol Med 32:797-803.

Beal MF (2005) Mitochondria take center stage in aging and neurodegeneration. Ann Neurol 58:495-505.

Beal MF, Matson WR, Swartz KJ, Gamache PH, Bird ED (1990) Kynurenine 
pathway measurements in Huntington's disease striatum: evidence for reduced formation of kynurenic acid. J Neurochem 55:1327-1339.

Benedetti A, Comporti M, Esterbauer H (1980) Identification of 4-hydroxynonenal as a cytotoxic product originating from the peroxidation of liver microsomal lipids. Biochim Biophys Acta 620:281-296.

Choi DK, Pennathur S, Perier C, Tieu K, Teismann P, Wu DC, Jackson-Lewis V, Vila M, Vonsattel JP, Heinecke JW, Przedborski S (2005) Ablation of the inflammatory enzyme myeloperoxidase mitigates features of Parkinson's disease in mice. J Neurosci 25:6594-6600.

Crow JP, Calingasan NY, Chen J, Hill JL, Beal MF (2005) Manganese porphyrin given at symptom onset markedly extends survival of ALS mice. Ann Neurol 58:258-265.

Dauer W, Przedborski S (2003) Parkinson's disease: mechanisms and models. Neuron 39:889-909.

Dexter DT, Wells FR, Agid F, Agid Y, Lees AJ, Jenner P, Marsden CD (1987) Increased nigral iron content in postmortem parkinsonian brain. Lancet 2:1219-1220.

Dexter DT, Carter CJ, Wells FR, Javoy-Agid F, Agid Y, Lees A, Jenner P, Marsden CD (1989) Basal lipid peroxidation in substantia nigra is increased in Parkinson's disease. J Neurochem 52:381-389.

Dexter DT, Holley AE, Flitter WD, Slater TF, Wells FR, Daniel SE, Lees AJ, Jenner P, Marsden CD (1994a) Increased levels of lipid hydroperoxides in the parkinsonian substantia nigra: an HPLC and ESR study. Mov Disord 9:92-97.

Dexter DT, Sian J, Rose S, Hindmarsh JG, Mann VM, Cooper JM, Wells FR, Daniel SE, Lees AJ, Schapira AH, Jenner P, Marsden CD (1994b) Indices of oxidative stress and mitochondrial function in individuals with incidental Lewy body disease. Ann Neurol 35:38-44.

Esterbauer H, Schaur RJ, Zollner H (1991) Chemistry and biochemistry of 4-hydroxynonenal, malonaldehyde and related aldehydes. Free Radic Biol Med 11:81-128.

Ferraro TN, Golden GT, DeMattei M, Hare TA, Fariello RG (1986) Effect of 1-methyl-4-phenyl-1,2,3,6-tetrahydropyridine (MPTP) on levels of glutathione in the extrapyramidal system of the mouse. Neuropharmacology 25:1071-1074.

Fessel JP, Hulette C, Powell S, Roberts II LJ, Zhang J (2003) Isofurans, but not F2-isoprostanes, are increased in the substantia nigra of patients with Parkinson's disease and with dementia with Lewy body disease. J Neurochem 85:645-650.

Gao HM, Hong JS, Zhang W, Liu B (2003) Synergistic dopaminergic neurotoxicity of the pesticide rotenone and inflammogen lipopolysaccharide: relevance to the etiology of Parkinson's disease. J Neurosci 23:1228-1236.

Gauuan PJ, Trova MP, Gregor-Boros L, Bocckino SB, Crapo JD, Day BJ (2002) Superoxide dismutase mimetics: synthesis and structure-activity relationship study of MnTBAP analogues. Bioorg Med Chem 10:3013-3021.

Giasson BI, Duda JE, Murray IV, Chen Q, Souza JM, Hurtig HI, Ischiropoulos H, Trojanowski JQ, Lee VM (2000) Oxidative damage linked to neurodegeneration by selective alpha-synuclein nitration in synucleinopathy lesions. Science 290:985-989.

Giovanni A, Sieber BA, Heikkila RE, Sonsalla PK (1991) Correlation between the neostriatal content of the 1-methyl-4-phenylpyridinium species and dopaminergic neurotoxicity following 1-methyl-4-phenyl1,2,3,6-tetrahydropyridine administration to several strains of mice. J Pharmacol Exp Ther 257:691-697.

Good PF, Hsu A, Werner P, Perl DP, Olanow CW (1998) Protein nitration in Parkinson's disease. J Neuropathol Exp Neurol 57:338-342.

Hensley K, Maidt ML, Yu Z, Sang H, Markesbery WR, Floyd RA (1998) Electrochemical analysis of protein nitrotyrosine and dityrosine in the Alzheimer brain indicates region-specific accumulation. J Neurosci 18:8126-8132.

Ischiropoulos $\mathrm{H}$, Zhu L, Chen J, Tsai M, Martin JC, Smith CD, Beckman JS (1992) Peroxynitrite-mediated tyrosine nitration catalyzed by superoxide dismutase. Arch Biochem Biophys 298:431-437.

Jellinger K, Paulus W, Grundke-Iqbal I, Riederer P, Youdim MB (1990) Brain iron and ferritin in Parkinson's and Alzheimer's diseases. J Neural Transm Park Dis Dement Sect 2:327-340.

Jenner P, Dexter DT, Sian J, Schapira AH, Marsden CD (1992) Oxidative stress as a cause of nigral cell death in Parkinson's disease and incidental Lewy body disease. The Royal Kings and Queens Parkinson's Disease Res Group. Ann Neurol 32 [Suppl]:S82-S87.

Jha N, Jurma O, Lalli G, Liu Y, Pettus EH, Greenamyre JT, Liu RM, Forman
HJ, Andersen JK (2000) Glutathione depletion in PC12 results in selective inhibition of mitochondrial complex I activity. Implications for Parkinson's disease. J Biol Chem 275:26096-26101.

Kachadourian R, Menzeleev R, Agha B, Bocckino SB, Day BJ (2002) Highperformance liquid chromatography with spectrophotometric and electrochemical detection of a series of manganese(III) cationic porphyrins. J Chromatogr B Analyt Technol Biomed Life Sci 767:61-67.

Klivenyi P, St Clair D, Wermer M, Yen HC, Oberley T, Yang L, Flint Beal M (1998) Manganese superoxide dismutase overexpression attenuates MPTP toxicity. Neurobiol Dis 5:253-258.

Lakritz J, Plopper CG, Buckpitt AR (1997) Validated high-performance liquid chromatography-electrochemical method for determination of glutathione and glutathione disulfide in small tissue samples. Anal Biochem 247:63-68.

Lan J, Jiang DH (1997) Excessive iron accumulation in the brain: a possible potential risk of neurodegeneration in Parkinson's disease. J Neural Transm 104:649-660.

Liang LP, Patel M (2004) Iron-sulfur enzyme mediated mitochondrial superoxide toxicity in experimental Parkinson's disease. J Neurochem 90:1076-1084.

Liang LP, Patel M (2006) Seizure-induced changes in mitochondrial redox status. Free Radic Biol Med 40:316-322.

Liang LP, Ho YS, Patel M (2000) Mitochondrial superoxide production in kainate-induced hippocampal damage. Neuroscience 101:563-570.

Mackensen GB, Patel M, Sheng H, Calvi CL, Batinic-Haberle I, Day BJ, Liang LP, Fridovich I, Crapo JD, Pearlstein RD, Warner DS (2001) Neuroprotection from delayed postischemic administration of a metalloporphyrin catalytic antioxidant. J Neurosci 21:4582-4592.

McGrath LT, McGleenon BM, Brennan S, McColl D, McILroy S, Passmore AP (2001) Increased oxidative stress in Alzheimer's disease as assessed with 4-hydroxynonenal but not malondialdehyde. Qjm 94:485-490.

Meister A, Anderson ME (1983) Glutathione. Annu Rev Biochem 52:711-760.

Misra HP, Fridovich I (1972) The role of superoxide anion in the autoxidation of epinephrine and a simple assay for superoxide dismutase. J Biol Chem 247:3170-3175.

Mlakar A, Spiteller G (1996) Previously unknown aldehydic lipid peroxidation compounds of arachidonic acid. Chem Phys Lipids 79:47-53.

Murphy TC, Amarnath V, Picklo Sr MJ (2003) Mitochondrial oxidation of 4-hydroxy-2-nonenal in rat cerebral cortex. J Neurochem 84:1313-1321.

Patel M, Day BJ (1999) Metalloporphyrin class of therapeutic catalytic antioxidants. Trends Pharmacol Sci 20:359-364.

Pennathur S, Jackson-Lewis V, Przedborski S, Heinecke JW (1999) Mass spectrometric quantification of 3-nitrotyrosine, ortho-tyrosine, and o,o'dityrosine in brain tissue of 1-methyl-4-phenyl-1,2,3, 6-tetrahydropyridine-treated mice, a model of oxidative stress in Parkinson's disease. J Biol Chem 274:34621-34628.

Perry TL, Godin DV, Hansen S (1982) Parkinson's disease: a disorder due to nigral glutathione deficiency? Neurosci Lett 33:305-310.

Przedborski S, Kostic V, Jackson-Lewis V, Naini AB, Simonetti S, Fahn S, Carlson E, Epstein CJ, Cadet JL (1992) Transgenic mice with increased $\mathrm{Cu} / \mathrm{Zn}$-superoxide dismutase activity are resistant to $\mathrm{N}$-methyl-4phenyl-1,2,3,6-tetrahydropyridine-induced neurotoxicity. J Neurosci $12: 1658-1667$.

Przedborski S, Jackson-Lewis V, Naini AB, Jakowec M, Petzinger G, Miller R, Akram M (2001a) The parkinsonian toxin 1-methyl-4-phenyl-1,2,3,6tetrahydropyridine (MPTP): a technical review of its utility and safety. J Neurochem 76:1265-1274.

Przedborski S, Chen Q, Vila M, Giasson BI, Djaldatti R, Vukosavic S, Souza JM, Jackson-Lewis V, Lee VM, Ischiropoulos H (2001b) Oxidative posttranslational modifications of alpha-synuclein in the 1-methyl-4-phenyl1,2,3,6-tetrahydropyridine (MPTP) mouse model of Parkinson's disease. J Neurochem 76:637-640.

Reed DJ, Savage MK (1995) Influence of metabolic inhibitors on mitochondrial permeability transition and glutathione status. Biochim Biophys Acta 1271:43-50.

Sayre LM, Smith MA, Perry G (2001) Chemistry and biochemistry of oxidative stress in neurodegenerative disease. Curr Med Chem 8:721-738.

Schapira AH, Cooper JM, Dexter D, Jenner P, Clark JB, Marsden CD (1989) Mitochondrial complex I deficiency in Parkinson's disease.[comment]. Lancet 1:1269.

Schapira AH, Cooper JM, Dexter D, Clark JB, Jenner P, Marsden CD (1990) 
Mitochondrial complex I deficiency in Parkinson's disease. J Neurochem 54:823-827.

Schapira AH, Hartley A, Cleeter MW, Cooper JM (1993) Free radicals and mitochondrial dysfunction in Parkinson's disease. Biochem Soc Trans 21:367-370.

Schulz JB, Matthews RT, Muqit MM, Browne SE, Beal MF (1995) Inhibition of neuronal nitric oxide synthase by 7-nitroindazole protects against MPTP-induced neurotoxicity in mice. J Neurochem 64:936-939.

Selley ML (1998) (E)-4-hydroxy-2-nonenal may be involved in the pathogenesis of Parkinson's disease. Free Radic Biol Med 25:169-174.

Sian J, Dexter DT, Lees AJ, Daniel S, Agid Y, Javoy-Agid F, Jenner P, Marsden CD (1994) Alterations in glutathione levels in Parkinson's disease and other neurodegenerative disorders affecting basal ganglia. Ann Neurol 36:348-355.

Sofic E, Riederer P, Heinsen H, Beckmann H, Reynolds GP, Hebenstreit G, Youdim MB (1988) Increased iron (III) and total iron content in post mortem substantia nigra of parkinsonian brain. J Neural Transm 74:199-205.

Trova MP, Gauuan PJ, Pechulis AD, Bubb SM, Bocckino SB, Crapo JD, Day BJ (2003) Superoxide dismutase mimetics. Part 2: Synthesis and structure-activity relationship of glyoxylate- and glyoxamide-derived metalloporphyrins. Bioorg Med Chem 11:2695-2707.

West MJ (1999) Stereological methods for estimating the total number of neurons and synapses: issues of precision and bias. Trends Neurosci 22:51-61.

Wu DC, Teismann P, Tieu K, Vila M, Jackson-Lewis V, Ischiropoulos H, Przedborski S (2003) NADPH oxidase mediates oxidative stress in the 1-methyl-4-phenyl-1,2,3,6-tetrahydropyridine model of Parkinson's disease. Proc Natl Acad Sci USA 100:6145-6150.

Yoritaka A, Hattori N, Uchida K, Tanaka M, Stadtman ER, Mizuno Y (1996) Immunohistochemical detection of 4-hydroxynonenal protein adducts in Parkinson disease. Proc Natl Acad Sci USA 93:2696-2701. 